\title{
Investigations in static response and free vibration of a functionally graded beam resting on elastic foundations
}

\author{
Abdelbaki Chikh \\ Department of Civil Engineering, Faculty of Applied Sciences, Ibn Khaldoun University, Tiaret, Algeria \\ cheikhabdelbakki@yahoo.fr
}

\begin{abstract}
In this article, an analytical study was done to predict the behavior of the beam vis-à-vis bending, buckling, and dynamic responses of isotropic homogeneous beams based on an elastic foundation. The material properties of the FG-beams vary across the thickness using the power law. In this work, the sinusoidal shear deformation beams theory is used to investigate the static and dynamic behavior of FG beams. The present theory fulfills the condition of nullity of edge stresses and does not require the use of a shear correction factor. Hamilton's principle is used to deduce equations of motion, and analytical solutions for simply supported beams were obtained using the Navier resolution method. Nondimensional displacements, eigenfrequencies and critical-buckling loads of isotropic homogeneous beams were obtained for various values of the foundation parameters. The numerical results obtained by the present technique have been compared with the results of literature and are in excellent agreement with them. It can be concluded that the current HSDBT is simple and accurate in solving the bending, eigenfrequency and critical-buckling load problems for FGM beams.
\end{abstract}

KEYwORDS. Undetermined integral terms; Free vibration; isotropichomogeneous beams; Navier's solution; Elasticity.

\section{open ACcess}

Citation: A. Chikh, Investigations in static response and free vibration of a functionally graded beam resting on elastic foundations, Frattura ed Integrità Strutturale, 51 (2020) 115-126.

Received: 08.10 .2019

Accepted: 04.11.2019

Published: 01.01.2020

Copyright: (c) 2020 This is an open access article under the terms of the CC-BY 4.0, which permits unrestricted use, distribution, and reproduction in any medium, provided the original author and source are credited.

\section{INTRODUCTION}

7 he functionally graded materials (FGM) may be defined as materials having a progressive variation of material properties. This material is produced by mixing two or more materials in a certain percentage of volume (ceramic and metal). The mixing ratio of the constituents varies regularly and the material properties change without any interruption throughout the thickness. There are a large number of works have been done on the dynamics, flexion and buckling behavior of FGM structures.

The Conventional composite structures suffer from a discontinuity in the properties of materials at the interface of layers and constituents. Therefore, constraint fields in intersection areas create interface problems and thermal stress concentrations in high-temperature environments. Many authors have studied the dynamic behavior of FGM beams, mostly, 
by means of both the classical beam theory (CBT), FSDBT and HSDBT Wang et al. [1] given a solution to solve the free vibration, buckling and bending problems of the Timoshenko and Euler-Bernoulli beams based on different models of elastic foundations.

There are many areas of application for composite materials (Chikh et al. [2]; Akbaş et al. [3]; Chikh et al. [4]; Fahsi et al. [5]) same the aircraft and aerospace industry. Omidi et al [6] studied the dynamic stability of simple supported FG beams reposing on a linear elastic foundation; with piezoelectric-layers under a periodic axial compression load. Zhong et al. [7] provided an analytical solution for console beams subjected to various types of mechanical loads. Thai et al. [8] studied the free vibration and bending of FG beams by the use of different higher-order beams theories. Zhu, H. [9] established threedimensional finite element model using finite element software to simulate and compare the stress performance of the strengthening beams with different numbers of CFRP plates. Bouchikhi, A. S et al. [10] investigated the 2D simulation used to calculate the J-integral of the main crack behavior emanating from a semicircular notch and double semicircular notch and its interaction with another crack which may occur in various positions in (TiB/Ti) FGM plate under mode I. Yassine Khalfi et al. [11] developed a refined and simple shear deformation theory for mechanical buckling of composite plate resting on two-parameter Pasternak's foundations. Meftah Kamel [12] presented a finite element method for analyzing the elasto-plastic plate bending problems. Saidi Hayat [13] presented a new shear deformation theory for free vibration analysis of simply supported rectangular functionally graded plate embedded in an elastic medium.

In this paper, a higher-order shear deformation beams theory for bending; buckling and free vibration of FG beams are developed. The present theory differs from other higher-order theories because, in present theory the displacement field which includes undetermined integral terms, which is not considered by the other researchers. The results of the present model are compared with the known data in the literature.

\section{VARIATIONAL FORMULATION AND CINEMATICS}

onsider an FG beam with length $\mathrm{L}$, width $\mathrm{b}$, and thickness $\mathrm{h}$ made of $\mathrm{Al} / \mathrm{Al}_{2} \mathrm{O}_{3}$ as represents in Fig. 1. The lower part of the FG-beam was totally ceramic and the upper surface was completely made of metal.

The beam $0 \leq \mathrm{x} \leq \mathrm{L} ;-\mathrm{b} / 2 \leq \mathrm{y} \leq \mathrm{b} / 2 ;-\mathrm{h} / 2 \leq \mathrm{z} \leq \mathrm{h} / 2$ in the Cartesian coordinate systems. assumed to be positive in the proposed direction, and the beam is deformed in the $\mathrm{x}-\mathrm{z}$ plane solely. The $\mathrm{x}$-axis coinciding with the beam inert axis. The beam is supported by Winkler-Pasternak foundations.

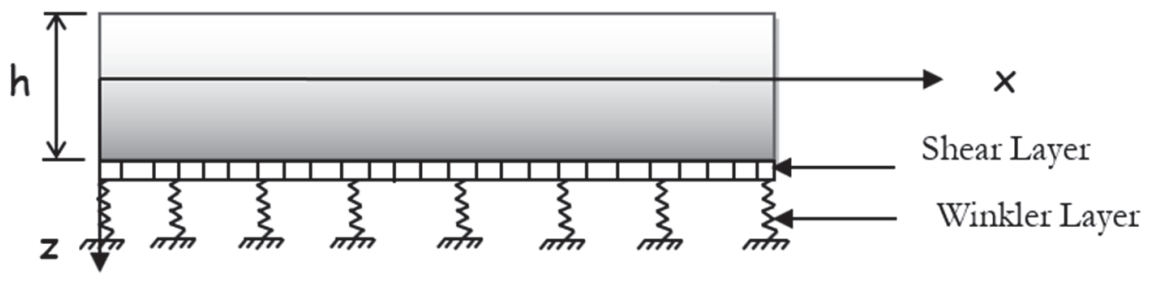

Figure 1: FGM beam supported by Winkler-Pasternak type elastic foundation.

\section{KINEMATICS AND CONSTITUTIVE EQUATIONS}

C $\mathrm{n}$ the fundamental of the assumptions expressed in the previous section, the displacement field of present theory can be obtained by:

$$
\begin{aligned}
& u(x, y, z, t)=u_{0}(x, y, t)-z \frac{\partial w_{0}(x, y, t)}{\partial x}+k_{1} f(z) \int \theta(x, y, t) d x \\
& w(x, y, z, t)=w_{0}(x, y, t)
\end{aligned}
$$

where:

$$
f(z)=\frac{h}{\pi} \sin \left(\frac{\pi z}{h}\right), g(z)=\frac{\partial f(z)}{\partial z}
$$


The deformations related to the displacement-field in Eq. (1) contains only three unknowns $\left(u_{0}, w_{0}, \theta\right)$. The linear strains corresponding with the displacement field in Eq. (1) are:

$$
\varepsilon_{x}=\varepsilon_{x}^{0}+z \varepsilon_{x}^{1}+f(z) \varepsilon_{x}^{2}, \gamma_{x z}=g(z) \gamma_{x z}^{0}
$$

where

$$
\varepsilon_{x}^{0}=\frac{\partial u_{0}(x, y, t)}{\partial x}, \varepsilon_{x}^{1}=-\frac{\partial^{2} w_{0}(x, y, t)}{\partial x^{2}}, \varepsilon_{x}^{2}=k_{1} A^{\prime} \theta(x, y, t), \gamma_{x z}^{0}=k_{1} \int \theta(x, y, t) d x
$$

The integral appearing in the above expressions shall be resolved by a Navier type solution and can be represented as:

$$
\int \theta d x=A^{\prime} \frac{\partial \theta}{\partial x}
$$

where the coefficient " $A^{\prime} "$ is depending on the type of solution chosen, in this case via Navier. Therefore, " $A^{\prime} "$ and $k_{1}$ is expressed as follows:

$$
A^{\prime}=-\frac{1}{\alpha^{2}}, k_{1}=\alpha^{2}
$$

According to the polynomial material law, the effective Young's modulus E(z)

$$
E(z)=E_{m}+\left(E_{c}-E_{m}\right)(0.5+q / h)^{p}
$$

The constitutive relations of an FG plate can be written as:

$$
\left\{\begin{array}{c}
\sigma_{x} \\
\sigma_{x z}
\end{array}\right\}=\left[\begin{array}{cc}
C_{11} & 0 \\
0 & C_{55}
\end{array}\right]\left\{\begin{array}{c}
\varepsilon_{x} \\
\gamma_{x v}
\end{array}\right\}
$$

where $C_{i j}$ are, the three-dimensional elastic constants given by:

$$
C_{11}=\frac{E(z)}{\left(1-v^{2}\right)}, C_{55}=\frac{E(z)}{2(1+v)}
$$

The equilibrium equations can be obtained using the Hamilton principle, in the present case yields:

$$
\begin{aligned}
& \int_{t_{1}}^{t_{2}}(\delta U-\delta V+\delta K) d t=0 \\
& \delta U=\int_{-b / 2 \Omega}^{b / 2}\left[\sigma_{x} \delta \varepsilon_{x}+\tau_{x z} \delta \gamma_{x z}\right] d \Omega d z, \\
& \delta V=\int_{\Omega}\left(q-f_{e}\right) \delta w d \Omega, \\
& \delta K=\int_{0}^{L} \int_{-b / 2}^{b / 2} \rho(z)(\ddot{u} \delta u+\ddot{w} \delta w) d z d y d x
\end{aligned}
$$


where $\Omega$ is the top surface, and $f_{e}$ is the density of reaction force of foundation. For the Pasternak foundation model:

$$
f_{e}=k_{w} w(x, y)-k_{p} \frac{\partial^{2} w(x, y)}{\partial x^{2}}
$$

The equilibrium equations can be acquired using the Hamilton principle.

$$
\begin{aligned}
& \delta u_{0}: \frac{\partial N_{x}}{\partial x}-I_{1} \frac{\partial^{2} u_{0}}{\partial t^{2}}+I_{2} \frac{\partial^{3} w_{0}}{\partial t^{2} \partial x}-I_{3} k_{1} A^{2} \frac{\partial^{3} \theta}{\partial t^{2} \partial x}=0 \\
& \delta w_{0}: \frac{\partial^{2} M_{x}^{b}}{\partial x^{2}}+q(x, t)+N_{0} \frac{\partial^{2} w_{0}}{\partial x^{2}}-f_{e}-I_{1} \frac{\partial^{2} w_{0}}{\partial t^{2}}-I_{2} \frac{\partial^{3} u_{0}}{\partial t^{2} \partial x}+I_{4} \frac{\partial^{4} w_{0}}{\partial t^{2} \partial x^{2}}+I_{5} \frac{\partial^{4} \theta}{\partial t^{2} \partial x^{2}}=0 \\
& \delta \theta: \quad k_{1} A^{\prime} \frac{\partial^{2} M_{x}^{s}}{\partial x^{2}}+k_{1} A^{\prime 2} \frac{\partial Q_{x x}}{\partial x}+I_{3} k_{1} A^{2} \frac{\partial^{2} u_{0}}{\partial t^{2} \partial x}-I_{5} k_{1} A^{\prime} \frac{\partial^{4} \theta}{\partial t^{2} \partial x^{2}}+I_{6} k_{1}^{2} A^{\prime 4} \frac{\partial^{4} \theta}{\partial t^{2} \partial x^{2}}=0
\end{aligned}
$$

where $\left(N_{x}\right)$ denote the resulting force in-plane, $\left(M_{x}^{b}\right),\left(M_{x}^{s}\right)$ denote the total moment resultants and $\left(Q_{x x}\right)$ are transverse shear stress resultants and they are defined as

$$
\begin{aligned}
& N_{x}=\int_{-b / 2}^{b / 2} \sigma_{x} d z, M_{x}^{b}=\int_{-b / 2}^{b / 2} \sigma_{x} z d z, \\
& M_{x}^{s}=\int_{-b / 2}^{b / 2} \sigma_{x} f(z) d z, Q_{x z}=\int_{-b / 2}^{b / 2} \sigma_{x z} g(z) d z
\end{aligned}
$$

Following the Navier solution process, we assume the following solution form for $\left(u_{0}, w_{0}, \theta\right)$ and that check the boundary conditions,

$$
\left\{\begin{array}{l}
u_{0} \\
w_{0} \\
\theta
\end{array}\right\}=\sum_{m=1}^{\infty}\left\{\begin{array}{l}
U \cos (\lambda x) \\
W \sin (\lambda x) \\
\theta \sin (\lambda x)
\end{array}\right\} e^{i \omega t}
$$

where $U, W$, and $\theta$ are arbitrary parameters to be determined, $\omega$ is the natural frequency, and $\lambda=\frac{m \pi}{L}$. The transverse load $q(x)$ is also expanded in Fourier series as:

$$
q(x)=\sum_{m=1}^{\infty} Q_{m} \sin (\lambda x)
$$

where

$$
Q_{m}=\frac{2}{L} \int_{0}^{L} q(x) \sin (\lambda x) d x
$$

In the case where a sinusoidally distributed load, we have

$$
m=1, Q_{1}=q_{0}
$$

In the case where uniform distributed the load, we have 


$$
m=1, Q_{m}=\frac{4 q_{0}}{m \pi},(m=1,3,5 \ldots)
$$

In the case where static problems, we have the following equation:

$$
[K]\{\Delta\}=\{F\}
$$

where $\{\Delta\}=\{U, W, \theta\}^{t}$ and $[K]$ is the symmetric matrix given by

$$
[K]=\left[\begin{array}{lll}
S_{11} & S_{12} & S_{13} \\
S_{12} & S_{22} & S_{23} \\
S_{13} & S_{23} & S_{33}
\end{array}\right]
$$

In the case of free vibration problem problems, the analytical solutions can be obtained by:

$$
\left([K]-\omega^{2}[M]\right)\{\Delta\}=0
$$

where $[M]$ is the symmetric matrix given by

$$
[M]=\left[\begin{array}{lll}
m_{11} & m_{12} & m_{13} \\
m_{12} & m_{22} & m_{23} \\
m_{13} & m_{23} & m_{33}
\end{array}\right]
$$

For buckling problems, can be expressed as

$$
([K]-\bar{N})\{\Delta\}=0
$$

in which:

$$
\begin{aligned}
& S_{11}=-A_{11} \lambda^{2}, S_{12}=B_{11} \lambda^{3}, S_{13}=k_{1} A^{\prime} \lambda D_{11}, \\
& S_{22}=\lambda^{4} E_{11} k_{1}-k_{p} \lambda^{2}-N_{0} \lambda^{2}-k_{w} \\
& S_{23}=-k_{1} A^{\prime} \lambda^{2} F_{11}, S_{33}=-k_{1}^{2} A^{\prime 3} A_{s 55} \lambda^{2}-k_{1}^{2} A^{\prime 2} G_{11}, \\
& m_{11}=I_{1}, m_{12}=-I_{2} \lambda, m_{13}=k_{1} A^{\prime} I_{3} \lambda, m_{22}=I_{1}+I_{4} \lambda \\
& m_{23}=-I_{5} \lambda^{2}, m_{33}=k_{1}^{2} A^{\prime 4} \lambda^{2} I_{6},
\end{aligned}
$$

where

$$
\begin{aligned}
& \left(A_{11}, B_{11}, D_{11}, E_{11}, F_{11}, G_{11}\right)=\int_{-b / 2}^{b / 2} C_{11}\left(1, z, f(z), z^{2}, z f(z), f(z)^{2}\right) d z, \\
& A_{55}^{s}=\int_{-b / 2}^{b / 2} C_{55} g(z)^{2} d z \\
& \left(I_{1}, I_{2}, I_{3}, I_{4}, I_{5}, I_{6}\right)=\int_{-b / 2}^{b / 2} \rho(z)\left(1, z, f(z), z^{2}, z f(z), f(z)^{2}\right) d z
\end{aligned}
$$




\section{RESULTS AND DISCUSSION}

$\mathrm{I}$ $\mathrm{n}$ this study, bending; buckling and free vibration investigation on SS FG beam by the present theory is suggested for investigation. The FG beams are made of Aluminum (Al; $\mathrm{E}_{\mathrm{m}}=70 \mathrm{GPa}, \varrho_{\mathrm{m}}=2702 \mathrm{~kg} / \mathrm{m}^{3}, \nu_{\mathrm{m}}=0.3$ ) and alumina $\left(\mathrm{Al}_{2} \mathrm{O}_{3} ; \mathrm{Ec}=380 \mathrm{GPa}, \varrho_{\mathrm{c}}=3960 \mathrm{~kg} / \mathrm{m}^{3}, \nu_{\mathrm{c}}=0.3\right)$ and their properties vary in the direction of the thickness of the beam according to power-law. The lower part of the FG-beam is rich in aluminum, while the upper part of the FG-beam is alumina rich. For convenience, the following dimensionless parameters are used:

$$
\bar{\omega}=\sqrt[4]{\frac{\rho_{c} A L^{4} \omega^{2}}{E I}}, \bar{w}(L / 2)=\frac{w(L / 2) 100 E_{c} I}{q L^{4}}, \bar{K}_{w}=\frac{k_{w} L^{4}}{E I}, \bar{K}_{p}=\frac{k_{p} L^{2}}{E I}, \bar{N}=\frac{N_{0} L^{2}}{E I}
$$

The buckling answer of an FG beam under axial force $\left(N_{0}\right)$ has been studied. A dimensionless; critical-buckling load is shown in Tab. 2. The critical-buckling load was obtained for various values regarding the foundation parameters $\bar{K}_{w}$ and $\bar{K}_{p}$. The results were contrasted with those delivered by Rao et al. [16]. Tab. 2 reveals that this study's results agreed with those available in the literature.

Tab. 3 present the comparisons of the dimensionless natural frequency obtained by the present beam theory with other beams theories results of Chen et al. [14] and Ying et al. [15] for three divers values of the thickness-to-length ratio, and for divers values of foundation parameters $\bar{K}_{w}$ and $\bar{K}_{p}$. As can be seen, the new results are in excellent concordat with previous ones.

\begin{tabular}{|c|c|c|c|c|c|c|c|c|c|c|}
\hline \multicolumn{2}{|c|}{$\begin{array}{l}\text { Foundation } \\
\text { Parameters }\end{array}$} & \multicolumn{3}{|c|}{$\mathrm{L} / \mathrm{h}=120$} & \multicolumn{3}{|c|}{$\mathrm{L} / \mathrm{h}=15$} & \multicolumn{3}{|c|}{$\mathrm{L} / \mathrm{h}=5$} \\
\hline $\bar{K}_{w}$ & $\bar{K}_{p}$ & $\begin{array}{l}\text { Chen et } \\
\text { al. [14] }\end{array}$ & $\begin{array}{l}\text { Ying et } \\
\text { al. [15] }\end{array}$ & Present & $\begin{array}{l}\text { Chen et } \\
\text { al. [14] }\end{array}$ & $\begin{array}{l}\text { Ying et } \\
\text { al. [15] }\end{array}$ & Present & $\begin{array}{l}\text { Chen et } \\
\text { al. [14] }\end{array}$ & $\begin{array}{l}\text { Ying et } \\
\text { al. [15] }\end{array}$ & Present \\
\hline \multirow{3}{*}{0} & 0 & 1.30229 & 1.30229 & 1.30416 & 1.31528 & 1.31527 & 1.30416 & 1.42026 & 1.42024 & 1.30416 \\
\hline & 10 & 0.64483 & 0.64483 & 0.64527 & 0.64835 & 0.64830 & 0.64527 & 0.67820 & 0.67451 & 0.64527 \\
\hline & 25 & 0.36611 & 0.36611 & 0.36624 & 0.36742 & 0.36735 & 0.36624 & 0.38170 & 0.37667 & 0.36624 \\
\hline \multirow{3}{*}{10} & 0 & 1.18057 & 1.18057 & 1.18210 & 1.19140 & 1.19134 & 1.18210 & 1.28260 & 1.27731 & 1.18210 \\
\hline & 10 & 0.61333 & 0.61333 & 0.61372 & 0.61656 & 0.61649 & 0.61372 & 0.64639 & 0.64025 & 0.61372 \\
\hline & 25 & 0.35567 & 0.35567 & 0.35579 & 0.35692 & 0.35684 & 0.35579 & 0.37206 & 0.36568 & 0.35579 \\
\hline \multirow{3}{*}{$10^{2}$} & 0 & 0.64007 & 0.64007 & 0.64051 & 0.64377 & 0.64343 & 0.64051 & 0.69610 & 0.66848 & 0.64051 \\
\hline & 10 & 0.42558 & 0.42558 & 0.42576 & 0.42741 & 0.42716 & 0.42576 & 0.45927 & 0.43881 & 0.42576 \\
\hline & 25 & 0.28285 & 0.28285 & 0.28291 & 0.28380 & 0.28360 & 0.28291 & 0.30516 & 0.28944 & 0.28291 \\
\hline
\end{tabular}

Table 1 Comparisons of the mid-span deflection $\bar{w}(L / 2)=\frac{w(L / 2) 100 E_{c} I}{q L^{4}}$ of an isotropic-homogeneous beam on elastic foundations due to a uniform pressure. 


\begin{tabular}{|c|c|c|c|c|c|}
\hline \multirow{2}{*}{$\bar{K}_{w}$} & \multirow{2}{*}{ Theories } & \multicolumn{4}{|l|}{$\bar{K}_{p} / \pi^{2}$} \\
\hline & & 0 & 0.5 & 1 & 2 \\
\hline \multirow[t]{2}{*}{0} & Rao et al. [16] & 9.8696 & 14.8040 & 19.7390 & 34.5440 \\
\hline & Present & 9.8538 & 14.7886 & 19.7234 & 29.5930 \\
\hline \multirow[t]{2}{*}{1} & Rao et al. [16] & 9.9709 & 14.9070 & 19.8410 & 34.6450 \\
\hline & Present & 9.9551 & 14.8899 & 19.8247 & 29.6943 \\
\hline \multirow[t]{2}{*}{$10^{2}$} & Rao et al. [16] & 20.0020 & 24.9370 & 29.8710 & 44.6760 \\
\hline & Present & 19.9859 & 24.9207 & 29.8555 & 39.7251 \\
\hline \multirow[t]{2}{*}{$10^{4}$} & Rao et al. [16] & 1023.1000 & 1028.0000 & 1032.9000 & 1047.7000 \\
\hline & Present & 1023.0656 & 1028.0004 & 1032.9352 & 1042.8048 \\
\hline
\end{tabular}

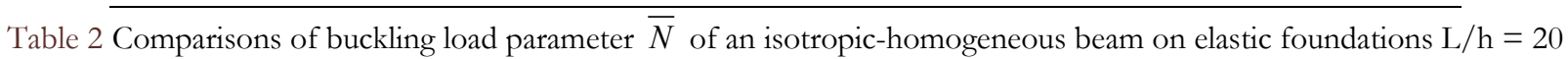

\begin{tabular}{|c|c|c|c|c|c|c|c|c|c|c|}
\hline \multicolumn{2}{|c|}{$\begin{array}{l}\text { Foundation } \\
\text { Parameters }\end{array}$} & \multicolumn{3}{|c|}{$\mathrm{L} / \mathrm{h}=120$} & \multicolumn{3}{|l|}{$\mathrm{L} / \mathrm{h}=15$} & \multicolumn{3}{|l|}{$\mathrm{L} / \mathrm{h}=5$} \\
\hline $\bar{K}_{w}$ & $\frac{\bar{K}_{p}}{\pi^{2}}$ & $\begin{array}{c}\text { Chen et al. } \\
\text { [14] }\end{array}$ & $\begin{array}{c}\text { Ying et al. } \\
\text { [15] }\end{array}$ & Present & $\begin{array}{c}\text { Chen et al. } \\
\text { [14] }\end{array}$ & $\begin{array}{l}\text { Ying et al. } \\
\text { [15] }\end{array}$ & Present & $\begin{array}{l}\text { Chen et } \\
\text { al. [14] }\end{array}$ & $\begin{array}{l}\text { Ying et } \\
\text { al. [15] }\end{array}$ & Present \\
\hline \multirow[t]{3}{*}{0} & 0 & 3.14143 & 3.14145 & 3.14028 & 3.13025 & 3.13227 & 3.13730 & 3.04799 & 3.06373 & 3.11161 \\
\hline & 1 & 3.73588 & 3.73587 & 3.73520 & 3.72657 & 3.72775 & 3.73165 & 3.65802 & 3.66645 & 3.70107 \\
\hline & 2.5 & 4.29687 & 4.29689 & 4.29646 & 4.28809 & 4.28886 & 4.29237 & 4.21834 & 4.22319 & 4.25717 \\
\hline \multirow[t]{3}{*}{$10^{2}$} & 0 & 3.74823 & 3.74823 & 3.74757 & 3.73895 & 3.74012 & 3.74400 & 3.67050 & 3.67882 & 3.71333 \\
\hline & 1 & 4.14356 & 4.14357 & 4.14309 & 4.13472 & 4.13558 & 4.13915 & 4.06636 & 4.07200 & 4.10521 \\
\hline & 2.5 & 4.58227 & 4.58227 & 4.58192 & 4.57347 & 4.57410 & 4.57757 & 4.49914 & 4.50278 & 4.53999 \\
\hline \multirow[t]{3}{*}{$10^{4}$} & 0 & 10.02403 & 10.02403 & 10.02407 & 9.99582 & 9.99583 & 10.01451 & 7.34081 & 7.34081 & 7.84931 \\
\hline & 1 & 10.04813 & 10.04812 & 10.04816 & 10.01970 & 10.01971 & 10.03857 & 7.34095 & 7.34095 & 7.84931 \\
\hline & 2.5 & 10.08394 & 10.08393 & 10.08398 & 10.05519 & 10.05520 & 10.07435 & 7.34116 & 7.34116 & 7.84931 \\
\hline
\end{tabular}

Table 3. Comparisons of the fundamental frequency parameter $\bar{\omega}=\sqrt[4]{\frac{\rho_{c} A L^{4} \omega^{2}}{E I}}$ of an isotropic-homogeneous beam on to elastic foundations using diverse beam theories 


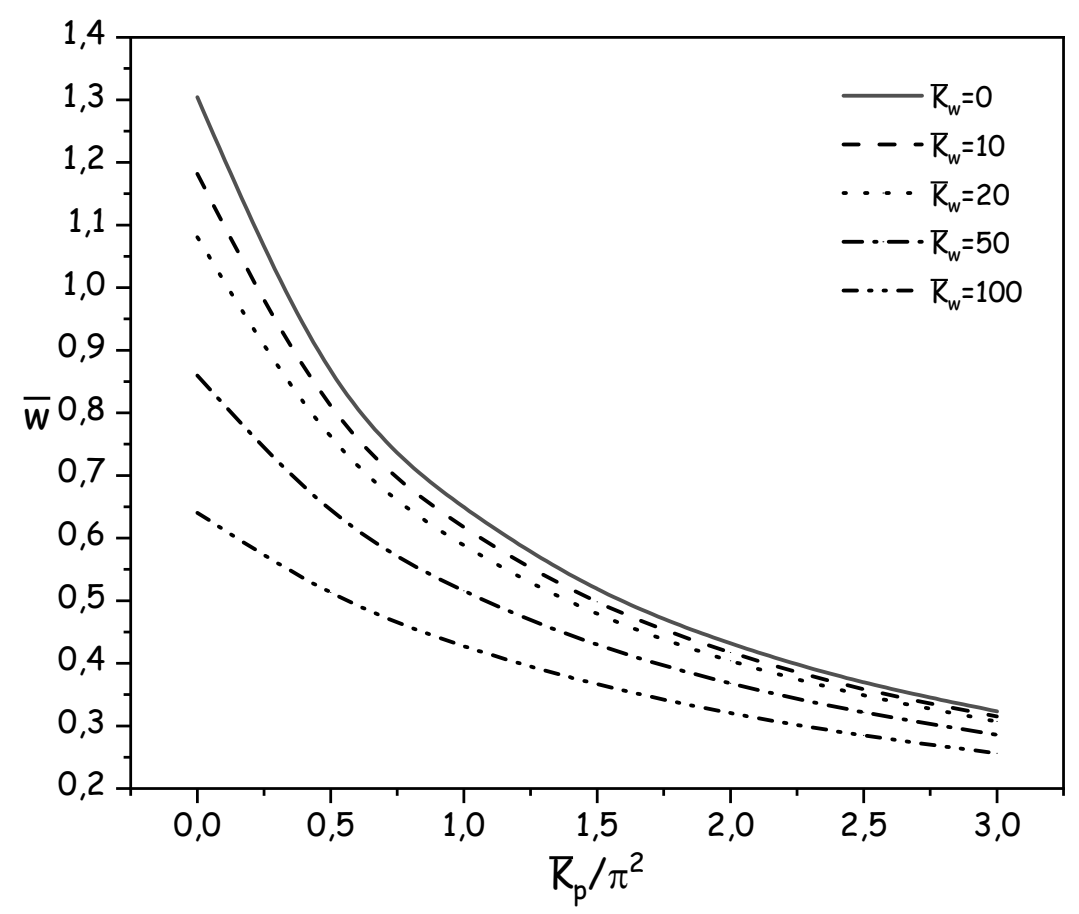

Figure 2: Variation of the non-dimensional transverse displacement $\bar{w}(L / 2)=\frac{w(L / 2) 100 E_{c} I}{q L^{4}}$ of an isotropic-homogeneous beam with Pasternak parameter $\bar{K}_{p}$ and Winkler parameter $\bar{K}_{w}$.

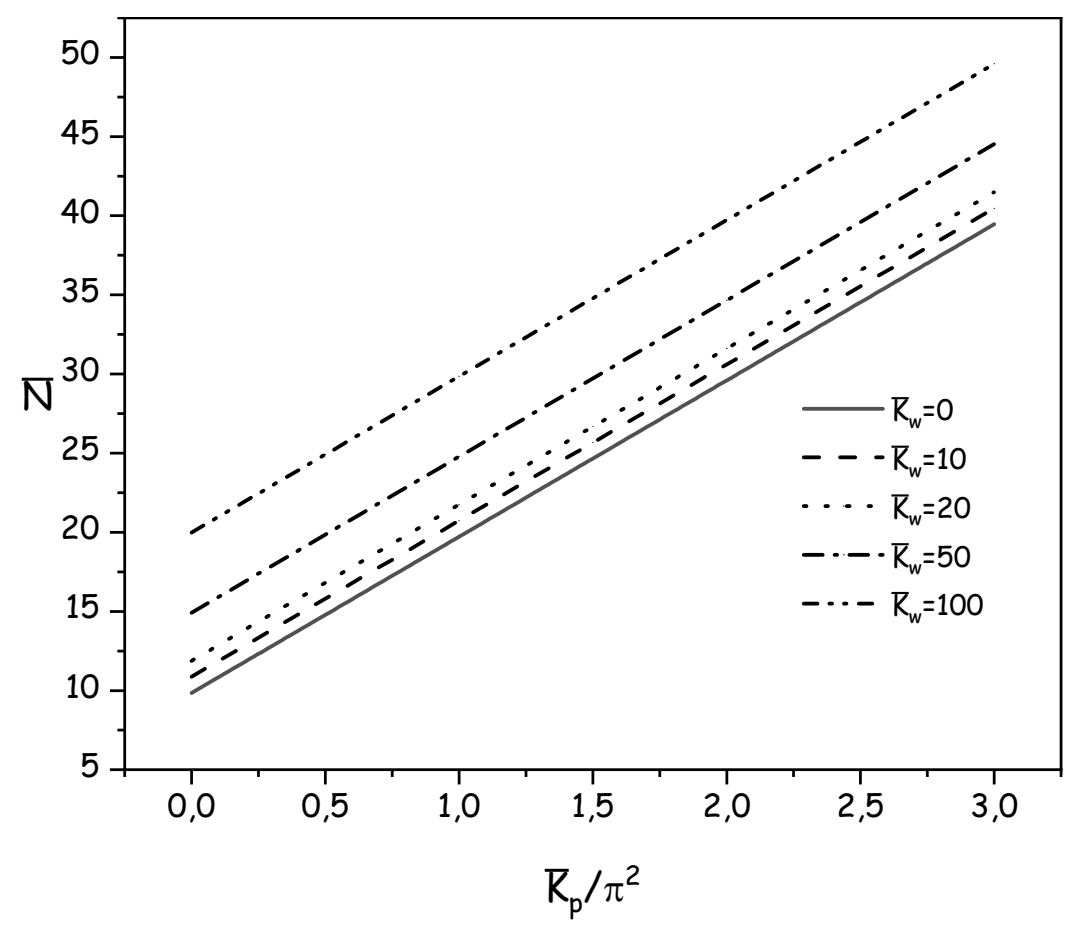

Figure 3: Variation of the non-dimensional buckling load parameter $\bar{N}$ of an isotropic-homogeneous beam with Pasternak parameter $\bar{K}_{p}$ and Winkler parameter $\bar{K}_{w}$. 


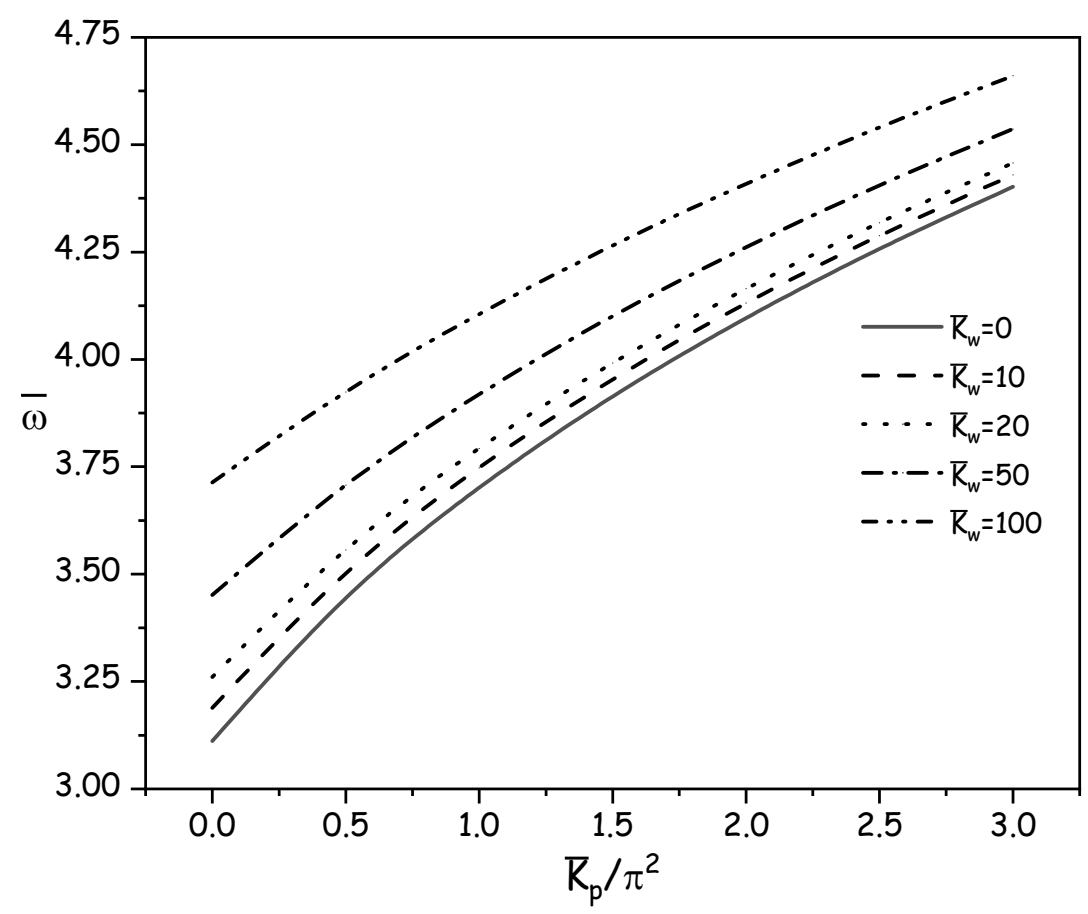

Figure 4: Variation of the nondimensional fundamental frequency $\bar{\omega}=\sqrt[4]{\frac{\rho_{c} A L^{4} \omega^{2}}{E I}}$ of isotropic homogeneous beam with Pasternak parameter $\bar{K}_{p}$ and Winkler parameter $\bar{K}_{w}$.

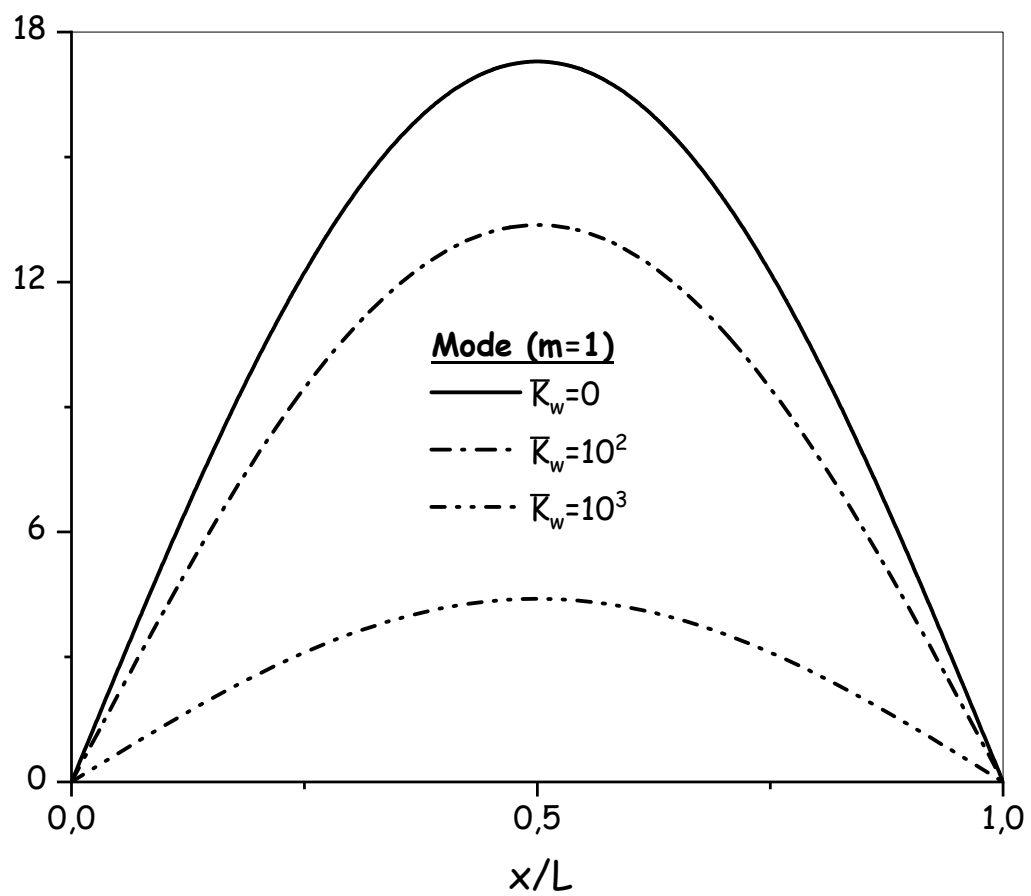

Figure 5: Mode shape of $\bar{w}$ at the base surface of the beam with various aspect ratios for the first mode frequency $\left(m=1, L / h=20, \bar{K}_{p} / \pi^{2}=2.5\right)$ 


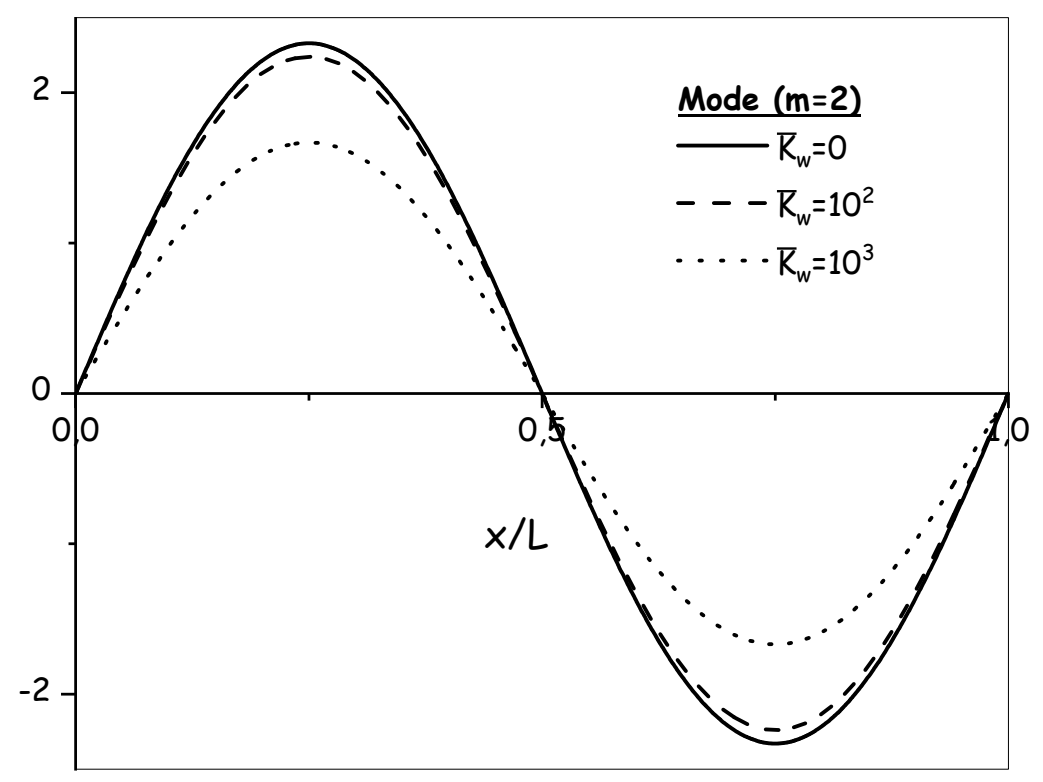

Figure 6: Mode shape of $\bar{w}$ at the base surface of the beam with various aspect ratios for the second mode frequency $\left(m=2, L / h=20, \bar{K}_{p} / \pi^{2}=2.5\right)$

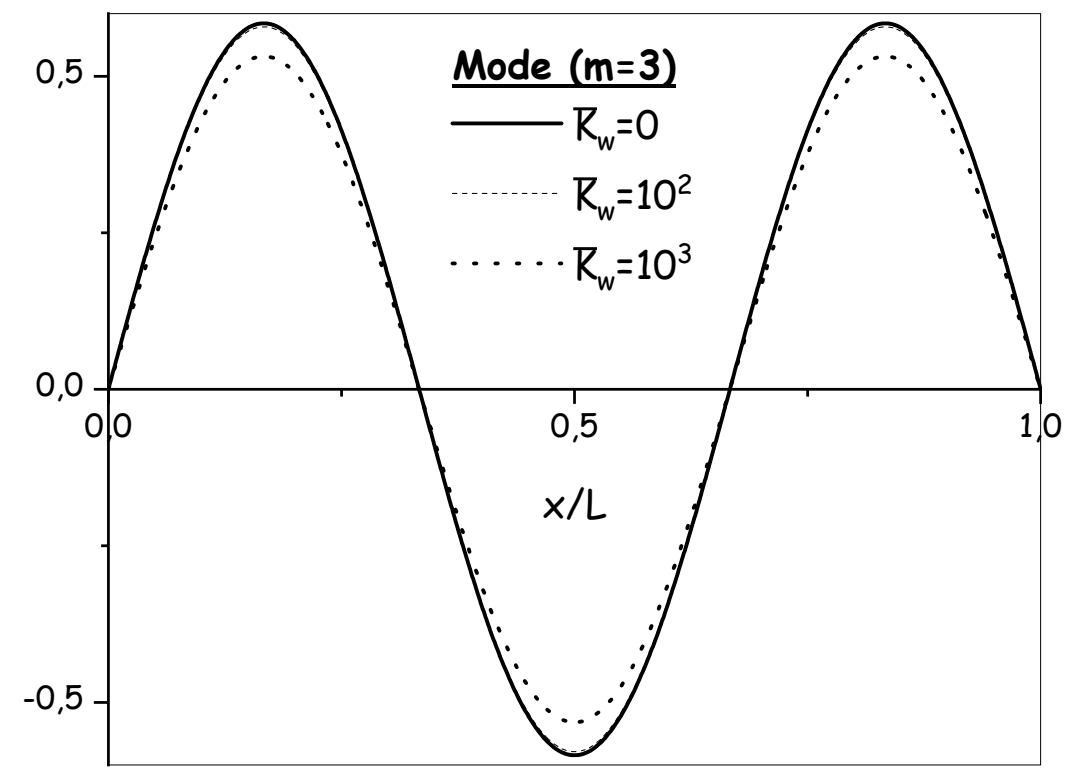

Figure 7: Mode shape of $\bar{w}$ at the base surface of the beam with various aspect ratios for the third mode frequency $\left(m=3, L / h=20, \bar{K}_{p} / \pi^{2}=2.5\right)$. 


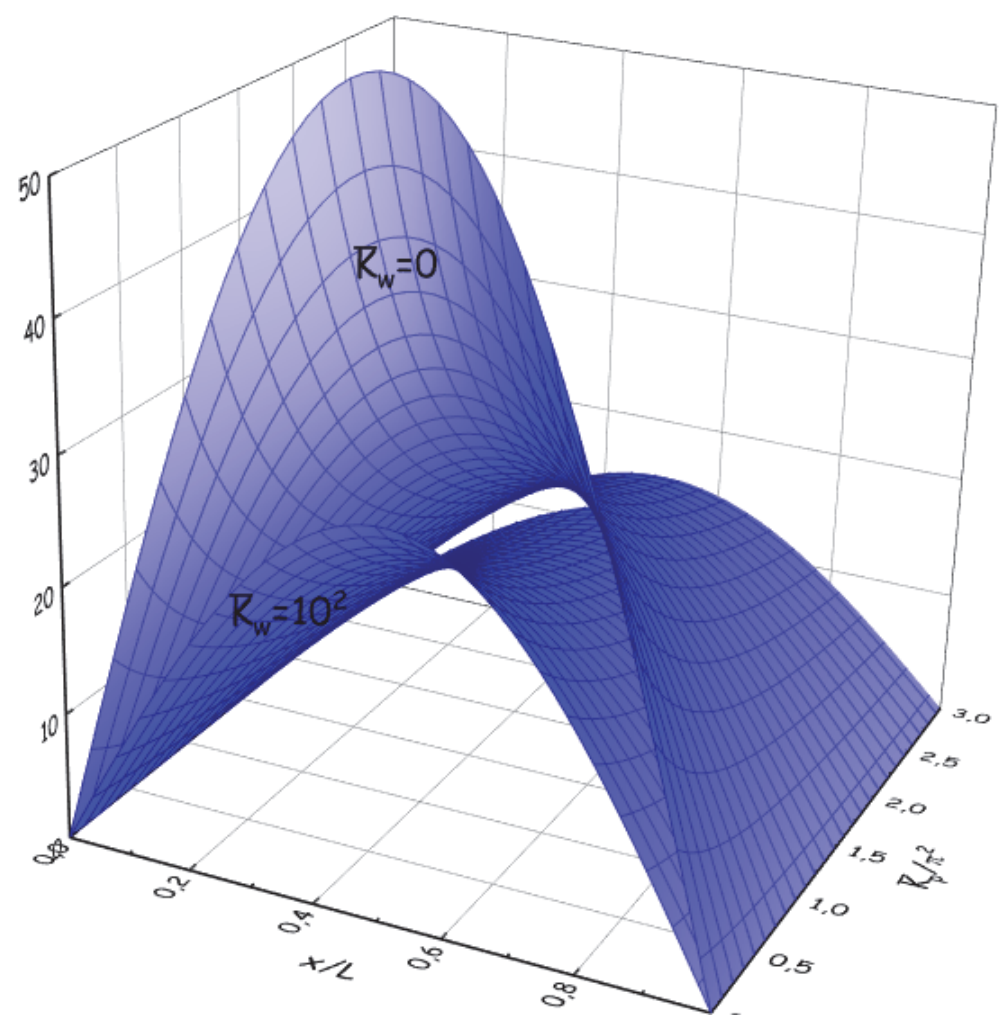

Figure 8: Effect of shear deformation, Pasternak parameter $\bar{K}_{p}$, and Winkler parameter $\bar{K}_{w}$ on the deflection of isotropic homogeneous beams under uniform load.

In Fig. 2, the non-dimensional transverse displacement is plotted against the Pasternak parameter and several values of the Winkler parameter. It can be drawn from this curve that the higher the Pasternak's foundation parameter, the lower the transverse displacement and the same thing for the Winkler parameter.

Fig. 3 presents the variation of the dimensionless critical-buckling load as a function of the Pasternak parameter and for various values of the Winkler parameter. It can be drawn from this curve that the dimensionless critical-buckling load increases linearly with the Pasternak parameter.

Fig. 4 presents the variation of the non-dimensional fundamental frequency in function of the Pasternak parameter and for various values of the Winkler parameter. It can be drawn from this curve that the higher the Pasternak's foundation parameter is, the higher the vibration frequency.

Figs. 5, 6 and 7 are respectively the first, second and third-order of mode shapes of the displacement $w$ at the lower surface of the isotropic homogeneous beam on an elastic foundation.

The impact of shear deformation on the deflection of FG beams is shown in Fig. 8 for various values of Pasternak parameter and tow values of Winker parameter $\left(\bar{K}_{w}=0, \bar{K}_{w}=10^{2}\right)$.

\section{CONCLUSION}

$\mathrm{I}$ $\mathrm{n}$ this paper; an efficient theory is presented for bending; free vibration and analysis of the dimensionless critical buckling load for functionally graded simply-supported beams reposed on two elastic parameters. This theory incorporates both shear deformation.

The governing equations and the boundary conditions are calculated using Hamilton's principle. The closed-form solutions are obtained by using Navier solution.

Numerical comparisons are made to illustrate the mastery of the current theory. The present theory satisfies the stress-free boundary conditions on the conditions on the upper and lower surfaces of the beam, and do not need a shear correction factor. 
Detailed mathematical formulations are given and numerical results are established, while the emphasis is set on examining the effect of the several parameters. The results of the actual theory are almost identical to each other and conform well with the existing solutions.

\section{REFERENCES}

[1] Wang, C. M., Lam, K. Y., and He, X. Q. (1998). Exact Solutions for Timoshenko Beams on Elastic Foundations Using Green's Functions*. Mechanics of Structures and Machines, 26(1), 101-113. DOI: 10.1080/089054598008945422.

[2] Chikh, A., Bakora, A., Heireche, H., Houari, M. S. A., Tounsi, A., and Bedia, E. A. A. (2016). Thermo-mechanical postbuckling of symmetric S-FGM plates resting on Pasternak elastic foundations using hyperbolic shear deformation theory. Structural Engineering and Mechanics, 57(4), 617-639. DOI:10.12989/sem.2016.57.4.617.

[3] Akbaş, Ş. D. (2015). Free vibration and bending of functionally graded beams resting on elastic foundation. Research on Engineering Structures and Materials, 1(1), 25-37. DOI:10.17515/resm2015.03st0107 .

[4] Chikh, A., Tounsi, A., Hebali, H., and Mahmoud, S. R. (2017). Thermal buckling analysis of cross-ply laminated plates using a simplified HSDT. Smart Structures and Systems, 19(3), 289-297. DOI: 10.12989/sss.2017.19.3.289.

[5] Fahsi, A., Tounsi, A., Hebali, H., Chikh, A., Bedia, E. A. A., and Mahmoud, S. R. (2017). A four variable refined nthorder shear deformation theory for mechanical and thermal buckling analysis of functionally graded plates. Geomechanics and Engineering, 13(3), 385-410. DOI: 10.12989/gae.2017.13.3.385.

[6] Omidi, N., Khorramabadi, M. K., and Niknejad, A. (2009). Dynamic stability of functionally graded beams with piezoelectric layers located on a continuous elastic foundation. Journal of Solid Mechanics, 1(2), 130-136. http://jsm.iau-arak.ac.ir/article_514296.html.

[7] Zhong, Z., and Yu, T. (2007). Analytical solution of a cantilever functionally graded beam. Composites Science and Technology, 67(3-4), 481-488. DOI: 10.1016/j.compscitech.2006.08.023.

[8] Thai, H.-T., and Vo, T. P. (2012). Bending and free vibration of functionally graded beams using various higher-order shear deformation beam theories. International Journal of Mechanical Sciences, 62(1), 57-66.

DOI: $10.1016 / j . i j m e c s c i .2012 .05 .014$.

[9] Hua Zhu. (2018). Stress performance of embedded carbon fiber reinforced plastics plate consolidated reinforced concrete structure. Frattura ed Integrità Strutturale, 12(46), 361-370. DOI: 10.3221/IGF-ESIS.46.33.

[10] Bouchikhi, A. S., Lousdad, A., Yassine, K., Bouida, N. E., Gouasmi, S., and Megueni, A. (2019). Finite Element Analysis of Interactions between two cracks in FGM notched Plate under Mechanical Loading. Frattura ed Integrità Strutturale, 13(48), 174-192. DOI: 10.3221/IGF-ESIS.48.20.

[11] Khalfi, Y., Bouchikhi, A. S., and Bellebna, Y. (2019). Mechanical stability investigation of advanced composite plates resting on elastic foundations using a new four-unknown refined theory. Frattura e Integrita Strutturale, (48), 208-221. DOI: $10.3221 /$ IGF-ESIS.48.22.

[12] Meftah, K., and Sedira, L. (2019). A nonlinear elasto-plastic analysis of Reissner-Mindlin plates by finite element method. Frattura ed Integrità Strutturale, 13(50), 276-285. DOI: 10.3221/IGF-ESIS.50.23.

[13] Saidi, H., and Sahla, M. (2019). Vibration analysis of functionally graded plates with porosity composed of a mixture of Aluminum (Al) and Alumina $\left(\mathrm{Al}_{2} \mathrm{O}_{3}\right)$ embedded in an elastic medium. Frattura ed Integrità Strutturale, 13(50), 286-299. DOI: $10.3221 /$ IGF-ESIS.50.24.

[14] Chen, W. Q., Lü, C. F., and Bian, Z. G. (2004). A mixed method for bending and free vibration of beams resting on a Pasternak elastic foundation. Applied Mathematical Modelling, 28(10), 877-890. DOI: 10.1016/j.apm.2004.04.001.

[15] Ying, J., Lü, C. F., and Chen, W. Q. (2008). Two-dimensional elasticity solutions for functionally graded beams resting on elastic foundations. Composite Structures, 84(3), 209-219. DOI: 10.1016/j.compstruct.2007.07.004

[16] Rao, G. V., and Raju, K. K. (2002). Elegant and accurate closed form solutions to predict vibration and buckling behaviour of slender beams on Pasternak foundation. Indian Journal of Engineering \& Materials Sciences, 9, 98-102. http://nopr.niscair.res.in/handle/123456789/19729. 